\title{
Conduct of Participants in The Retail Market for Metal Products in Kakamega County, Kenya
}

\author{
Tsuma M.C ${ }^{1}$, Ngala $C^{2}$, Byaruhanga $\mathrm{J}^{3}$. \\ ${ }^{I}$ Department of Economics, Masinde Muliro University of Science and Technology \\ ${ }^{2}$ School of Business and Economics, Masinde Muliro University of Science and Technology \\ ${ }^{3}$ School of Business and Economics, Masinde Muliro University of Science and Technology
}

\begin{abstract}
This paper investigates the conduct of participants in the retail market for metal products in Kakamega County, Kenya in bid to assess its competitiveness. The primary data used to analyze the market conduct is based principally on a sample of 249 respondents interviewed in 2015 in the Towns of Kakamega and Mumias. Descriptive survey and causal designs were employed due to their suitability in detailing the market conditions and in hypothesis testing. The results indicate that conduct in the retail market for metal products was influenced mainly by product promotion (displaying and giving discounts) and business networks while prices were determined through a mix of strategies including vertical coordination and collusion, thus confirming (Koutsoyianni's, 1993) observation that no industry is perfectly competitive. The findings have distinct policy relevance in several respects. First, they point to the need to formulate regulations requiring prices for metal products be displayed and that standard weights and measures be used in the entire retail market. This can ensure that the consumer is given the necessary market information in order to make rational decisions. Secondly, there is need for regulations calling on enterprises to join business associations/networks to enhance access to and utilization of market information. Thirdly, appropriate tariff rates for information, communication and technology as well as social media should be formulated to contribute to consumer enlightenment and product promotion. Finally, there is need for continuous reduction in opportunities for exploiting imperfectly informed buyers and sellers further helping to maintain competitive business conduct as well as markets.
\end{abstract}

Keywords: Conduct, Participants, Retail Market, Metal Products

\section{Introduction}

The paper analyzes the conduct of participants in the retail market for metal products in Kakamega County, Kenya in an effort to ascertain the nature and intensity of competition. The metal products sector has gained international prominence due to practical applicability in various sectors. Based on the International Standards of Industrial Classifications of all Economic Activities (ISIC), the codes for manufacture of metal products range from 2410 (Manufacture of iron and steel) to code 2599 (Manufacture of other fabricated metal products not elsewhere classified) (UNIDO, 2011; 2015; GOK, 2010).

The multi-use nature of iron and steel to produce a wide variety of products for use across sectors has endeared many Governments around the globe to prioritize manufacturing of metal products (UNIDO, 2015). This is because these products can be used in sectors such as defence, transport, heavy engineering, energy, construction- including structural, aeuronetical and shipping. Metal products are also closely linked to chemical and light industry, thus showing that investments in iron and steel industries has the potential to contribute to competitiveness and growth of the regional, national and local economies (Delloitte, 2015; WSD, 2013; UN, 2011).

In an effort to spur growth in the Manufacturing sector, the Government continues to promote the micro, small and medium scale enterprises as vehicles for employment creation and poverty reduction (GOK, 2015). These enterprises create job opportunities since they are labour and skills - intensive. In sum, they reduce income inequalities and train indigenous entrepreneurs for future manufacturing industry employment (Delloite, 2013; Hanh, 2005).

According to the Kakamega County Revenue Department, the agents of metal products deal in a wide range of products including; steel, structural metal products (window frames, doors, prefab buildings, etc.); cutlery, tools, kitchenware and general hardware; boilers, metal tanks and containers, steam generators; forging, metal coating, turning, welding; and metal casting; and more (GOK, 2014).

Reforms in the Kenyan SME sector have resulted in two opposite forces. While the policy and regulatory changes are expected to bring in greater competition in the market and, thereby, to enhance efficiency of the firms, the strategic responses of these firms are likely to limit market competition in pursuit of profits or returns. Thus there is need for a comprehensive study to understand the market dynamics of micro, small and 
medium scale enterprises and particularly focusing on metal products industry and thus design policies to foster competition (KPSA, 2015).

Most studies on market structure have been undertaken in the large liberalized markets of America and the European Union. Few studies focus on localized but liberalized makets such as Kakamega County. Classical economic wisdom suggests that comprehending the fundamental forces that drive an industry is vital to its success and to the individual firms that compete in it (Chamberlain, 1933, cited in Kibwage, 2008; Bain, 1951, cited in Ma, 2008; Tregenna, 2009).

One of the factors influencing competition in the metal products sector arises from the fact that most inputs are imported and subject to international demand - supply pressures,Secondly, the sector is undergoing rapid technologically induced changes that are delivering dynamic products to fit the dynamic market needs. Thirdly, the market participants whose number and size distribution are changing rapidly are in transitional state of learning the art and skills to maximize technical and economic efficiency in the production and marketing of metal products (KPSA, 2015). Further, major manufacturers of metal products are located in Nairobi and Mombasa, thus indicating existence of mobility barriers, since it takes time, efforts and resources to move into new industries (GOK, 2010).

Again, the market for metal products is dynamic and faces stiff competition- based on pricing and quality differences - from substitutes of clay, stone, bricks, blocks, wood, plastic, bamboo, pulp, organic briquettes and fibre. Also, overreliance on local markets and unfavourable zoning regulations are cited as an impediment to the growth of the sector (GOK, 2014; KPSA, 2015; CGK, 2013).

Thus faced with international trade dynamics, stiff competition as well as serving localized markets presents an opportunity to explore how the market for metal products - which appear to perform well nationally - responds to the stated challenges and whether market potentials exist within the study area to attract investors in the fields of metal products manufacturing, transportation, warehousing and advertising that may lead to price stability and job creation (GOK, 2015; World Bank; 2014). This can only be done if the market conduct of participants in the retail market for metal products in Kakamega County is ascertained.

\section{Market Conduct Constructs}

The paper reviews literature on market conduct in terms of advertising, research and innovation as essential constructs of conduct.

\subsection{Advertising and performance of industry}

Scherer \& Ross (1990 cited in Clay and Werner, 2003)suggested the conduct in the SCP model was related with the firms' product strategies, innovation and advertising. More recently it has been noted that the basic ideas underlying the S-C-P-paradigm can be useful for assessing within industry competition of crucial importance for the firms choice of strategy (Caves, 1980 cited in Durling and Thomas, 2006). The SCP paradigm implies that structural changes may lead to subsequent changes in industry behaviour and industry performance. Such changes can be initiated by governmental interventions (Yu and Neus, 2005; JMD, 2015).

Market conduct is a set of competitive strategies that firms adopted as a result of other factors, especially market structure. The conduct of a market includes pricing behaviour, product/project strategy and advertising, research and innovation, market investment, and legal tactics(OECD,2015d); these enable competing firms to coordinate and adapt to each other to eliminate the potential entry or existing competition. The market conduct simply describe the behaviour of the firms in order to make profit and increase their market share in their relevant markets based upon the supply and demand condition (Puller, 2007).

Konings and Hylke (2005) establish that firms can apply one or a combination of strategies based on market dynamics, opportunities and threats. These strategies can range from having own selling point (for localized markets) to opening up several branches (for firms serving different markets). Other strategies identified by literature include; collusive behavior to maximize market share, selling differentiated products in several markets and thus charging different prices, running a low cost structure which enables a firm to increase profits by reducing prices and expanding market share (Liebman, 2006; Byaruhanga, 2002).

\subsection{Research and Innovation}

Liebman (2006) and Puller (2007) argue that under certain reasonable conditions firms with competition pressure are more likely to invest in Research and Development (R \& D) models that stimulate more intense product market competition, as increases in the substitutability between differentiated products, reduces post-entry rents, and therefore, reduces the equilibrium number of entrants. Puller (2007) finds that an increase in product market competition has a negative effect on productivity growth by reducing the monopoly rents that reward new innovation (Konings, 2005).

Aghion, et al (2005) finds that the threat of technologically advanced entry spurs innovation incentives in sectors close to the technology frontier, where successful innovation allows incumbents to survive the threat. Hrazdil and Zhang (2012) conclude that firms with high levels of technological competence are more likely to 
increase research and development investments when facing intensifying market competition pressure, whereas firms with low technological competence tent to reduce such investments (Durling, 2006).

\subsection{Research Design}

\section{Methodology}

The study used descriptive survey and causal designs. Descriptive survey design was used to obtain information concerning the current status of the conduct of market participants and to describe "what exists" with respect to variables under study. Causal design (multiple regression model) was used to measure what impact a specific change will have on existing norms and assumptions within the market conduct constructs. This design was suitable because it enabled testing of hypotheses as well as help explain how variation in one phenomenon, an independent variable, leads to or results, on average, in variation in another phenomenon, the dependent variable (Kothari, 2004).

\subsection{Study Area}

The study was undertaken in Kakamega and Mumias Towns of Kakamega County. The County covers a total area of $3051.2 \mathrm{~km}^{2}$ (G.o.K, 2009). Kakamega and Mumias towns were selected for the study because they host the highest proportion of metal enterprises and are also the biggest beneficiaries of the massive county infrastructure improvement programme.The population for the study comprised of 701 registered retail enterprises dealing in metal products and operating within Kakamega (421 enterprises) and Mumias (280) Towns of Kakamega County.

\subsection{Sample Size}

The sample size was determined using Cochran 1963 formula: $\mathrm{n}_{0}=\mathrm{z}^{2} \mathrm{pq} / \mathrm{e}^{2}$,

where;

$\mathrm{n}_{0}=$ calculated sample size,

$\mathrm{p}=$ maximum variability

$\mathrm{q}=1-\mathrm{p}$ and $\mathrm{e}=$ desired level of precision

$\mathrm{n}_{0}=(1.96)^{2}(.5)(.5) /(0.05)^{2}=385$

True sample for the study population of 701 was computed thus;

$$
\begin{aligned}
& n=\frac{n_{0}}{1+\left(\frac{n_{0}-1}{N}\right)} \\
& n=\frac{385}{1+\left(\frac{385-1}{701}\right)} \\
& n=\frac{385}{1.5478} \\
& n=249
\end{aligned}
$$

Table 1 shows the distribution of the sample respondents in the study area.

Table 1: Sample Distribution

\begin{tabular}{|l|l|l|l|l|l|}
\hline S/No & \multirow{2}{*}{$\begin{array}{l}\text { Enterprise } \\
\text { description }\end{array}$} & Population & Geographic spread of sample size & \multirow{2}{*}{ No of Respondents } \\
\cline { 4 - 5 } & & & Kakamega & Mumias & \\
\hline 1 & Medium & 170 & 36 & 24 & 60 \\
\hline 2 & Small & 234 & 50 & 33 & 83 \\
\hline 3 & Micro & 120 & 26 & 17 & 43 \\
\hline 4 & Large & 177 & 38 & 25 & 63 \\
\hline & & $\mathbf{7 0 1}$ & $\mathbf{1 5 0}$ & $\mathbf{9 9}$ & $\mathbf{2 4 9}$ \\
\hline
\end{tabular}

The specific sample distribution for each town was computed as follows;

$\mathrm{n}_{\mathrm{d}}=\mathrm{N}_{\mathrm{p}} / 701 * 249$ where $\mathrm{n}_{\mathrm{d}}$ is the distributed sample and $\mathrm{N}_{\mathrm{P}}$ is the distributed study population

The result obtained is then distributed proportionately using 0.6 and 0.4 for Kakamega and Mumias towns respectively. Thus total sample for medium category for Kakamega and Mumias towns was computed as $\mathrm{n}_{\mathrm{dk}}=170 / 701 * 249=60$ and distributed as $(60 * 0.6=36$ and $60 * 0.4=24$ for Kakamega and Mumias 
respectively). Applying the same concept ensured that all the 249 respondents were distributed across all the enterprise types with a total of 150 and 99 respondents for Kakamega and Mumias Towns respectively.

\subsection{Data Collection}

\subsubsection{Data Collection Methods}

The study utilized both qualitative and quantitative data. Both primary and secondary data was used in the study. Primary data was collected through structured questionnaires, which were ideal because they provided an opportunity for respondents to provide detailed responses. They also allowed respondents to openly express themselves and served low - literacy respondents conveniently levels since the research assistants helped to translate or simply the questions further. Primary data collected on market structure constructs included; the number of firms in the metal products industry, average monthly turnover and asset value.

Secondary data on the other hand were collected from various sources such as archival records comprised of journals, market competition publications, policy documents, Acts of Parliament, official reports, internet and any other relevant literature. These sources yielded information on enterprise profile, including business types, legal orientation, enterprise ownership and years in operation. Additionally, secondary sources generated information used to enrich the findings and discussion.

\subsubsection{Analytical Techniques}

This paper utilized the Structure, Conduct and Performance (SCP) Paradigm which has been used widely as a basic tool to analyze the cause and effects relationships of the market conditions, its conduct, structure and the resulting performance of industries (Scherer and Ross, 1990 cited in Faulkner and Campell, 2003). To identify sets of attributes or variables that influence economic performance of a market sector and to build theories detailing the links between these attributes and the end performance, the SCP paradigm is commonly used as a broad descriptive model.

Market conduct refers to the patterns of behaviour that firms follow in adapting or adjusting to the markets in which they sell or buy (Bain, 1959, cited in Tregenna, (2009). This implies the analysis of human behavioral patterns that are not readily identifiable, obtainable, or quantifiable. Therefore conduct variables were treated in a descriptive manner. Analysis of conduct focused on pricing strategies, Research and Development intensity and development of new technologies, joint profit maximization (cartels, price leadership, collusion and mergers) and price discrimination.

This study utilized Khambampati (1996) simultaneous equations approach. This approach contains three different models assuming that each of conduct $(\mathrm{C})$, structure $(\mathrm{S})$, and performance $(\mathrm{P})$ is a function of the other two aspects, that is;

$\mathrm{S}=\mathrm{f}_{1}(\mathrm{C}, \mathrm{P}), \mathrm{C}=\mathrm{f}_{2}(\mathrm{~S}, \mathrm{P}), \mathrm{P}=\mathrm{f}_{3}(\mathrm{~S}, \mathrm{C})$

In this study, advertising intensity (AD) was taken as a proxy for conduct. This paper adopted the advertising equation as used by Tung, (2008) and Park, (2006), in the form of:

$\mathrm{AD}=\mathrm{b}_{0}+\mathrm{b}_{1} \mathrm{MS}+\mathrm{b}_{2} \mathrm{PF}+\mathrm{b}_{3} \mathrm{CR}+\mathrm{b}_{4} \mathrm{CR}_{4}^{2}+\mathrm{b}_{5} \mathrm{SG}+\mathrm{b}_{6} \mathrm{ISAG}$

\subsubsection{Observation of Ethical Standards}

Utmost care was taken to ensure strict observation of ethical principles and standards. This involved seeking a permit for research authorization from the National Commission of Science, Technology and Innovation (NACOSTI). Every participant in the study was notified of the aims, methods, benefits and his/her rights to decline participation in the research.The identity of respondents and information provided by them was kept strictly confidential. All data and information sources were duly acknowledged and plagiarism was avoided. Confidentiality and privacy was guaranteed as well as the consent and anonymity of the respondents throughout the study. Participation in the study was on voluntary basis and informed consent. The self - esteem and self-respect of the participants was never violated.

\section{Results and Discussion}

The analysis of conduct of market participantssought to establish the price-setting conduct/behaviour and strategies to establish competitive edge over rivals such as sales promotion, and product production policies.

Conduct refers to the pattern of behavior which retailers follow in adapting or adjusting to the market in which they operate (Bain, 1959). Dimensions of market conduct analysed include; (i) Product and sales promotion policies including the presence/ absence of coercive tactics towards existing rivals or potential market entrants and (ii) methods employed by firms (retailers) in determining prices and output. 
Table 2: Empirical Results of SCP Model of the retail market for metal products

\begin{tabular}{|l|l|l|}
\hline Variable & Mean & Standard Deviation \\
\hline AD & 0.015 & 0.00095 \\
\hline MS & 0.399 & 0.0245 \\
\hline PF & 0.030 & 0.004 \\
\hline CR $_{4}$ & 0.27 & 0.116 \\
\hline SG & 0.021 & 0.0029 \\
\hline ISAG & 0.023 & 0.0064 \\
\hline MES & $0.0307^{\mathrm{b}}$ & 0.0074 \\
\hline K & 1251.3 & 148.54 \\
\hline L & $0.018^{\mathrm{a}}$ & 0.0018 \\
\hline TOC & $0.019^{\mathrm{b}}$ & 0.0021 \\
\hline BRANCH & 0.21 & 0.018 \\
\hline INTL & 0.17 & 0.018 \\
\hline CLASS & 0.62 & 0.013 \\
\hline
\end{tabular}

Note: a: Employ/million Kshs. b: Billion Kshs.

Survey Data, 2015

The empirical results from Table 2 shows that market structure, conduct and performance of the retail market for metal products in Kakamega County is also determined by a variety of variables relating to structure of the market (market share, number of enterprise branches, concentration, capital intensity and labour intensity), conducts of the firms (advertising intensity, international brands and enterprise class), and other aspects of performance (profitability, sales growth rate, industrial sales growth rate, minimum efficiency scale and total operating costs). This means that there are strong inter-linkages between market structure, business strategies and financial performance in the metal products sector.

Not only is the financial performance of the retail market for metal products is influenced by their conduct and structure of the market, but there are also strong feedback effects from performance to conduct and from conduct to structure. In the Kakamega County context, all these essentially make the SCP relationships multidirectional and dynamic in nature.

\subsection{Advertising Intensity}

To understand how firms and the industry in totality tried to influence sales, the respondents were asked to state the proportion of advertising expenditure in relation to return on sales.

Table 3 shows the results averaged for the four main product categories.

Table 3: Proportion of Advertising Expenditure in relation to Return on Sales

\begin{tabular}{|l|l|}
\hline Firms & Average advertising expenditure \\
\hline Micro scale & 0.116 \\
\hline Large scale & 0.124 \\
\hline Medium scale & 0.015 \\
\hline Small scale & 0.014 \\
\hline Average & $\mathbf{0 . 0 1 5}$ \\
\hline
\end{tabular}

Survey Data, 2015

The data shows that advertising expenditure (the mean of advertising expenditure / return on sales) was maintained at less than $1 \%$ of the total return on sales for all categories of steel products. The implication of this is that managers and dealers in metal products speculating on the effects of advertising on sales. The results indicate that firms with larger turnover could be willing to spend more on advertising to increase sales and market share.

Tung, (2008), observed that, advertising by large chains provides greater sophistication that promotes their particular segments, styles, and types of products. The results suggested that internationally rated firms are more willing than localised to promote their services through advertising. The profit variable is not found to be significant in the advertising equation, (see equation 2). The firms gain from their market share and are not intent in advertising by their profit.To detect the effect of market conduct on profitability, analysis of market conduct equation derived from empirical data was conducted (Table 4).

Table 4: 3 SLS Estimates of Market Conduct, Structure and Performance

\begin{tabular}{|l|l|l|l|}
\hline Variables & $($ MS $)$ Market Share & (AD) Advertising & (PF) Profitability \\
\hline Constant & $-0.03192( \pm 0.13084)$ & $-0.703( \pm 0.26009)$ & $-0.9429( \pm 0.01732)$ \\
\hline AD & $-0.1151 *( \pm 0.07616)$ & & $0.2330 *( \pm 0.4068)$ \\
\hline MS & & $0.95961 *( \pm 0.0642)$ & $1.011 *( \pm 0.5410)$ \\
\hline PF & $0.4365( \pm 7.041)$ & $0.004( \pm 0.006)$ & \\
\hline
\end{tabular}




\begin{tabular}{|l|l|l|l|}
\hline $\mathrm{CR}_{4}$ & & $1.325( \pm 6.001)$ & $-6.001( \pm 9.721)$ \\
\hline $\mathrm{CR}_{4}{ }^{2}$ & & $-2.0181( \pm 13.156)$ & \\
\hline $\mathrm{SG}$ & $-0.0434( \pm 0.016)$ & $-0.0231^{*}( \pm 0.014$ & \\
\hline ISAG & $0.271( \pm 0.0570)$ & $0.149^{* *}( \pm 0.0239)$ & $-1.046( \pm 0.0329)$ \\
\hline $\mathrm{MES}$ & & & $0.458( \pm 0.304)$ \\
\hline $\mathrm{K}$ & & & $-0.087^{* *}( \pm 0.006)$ \\
\hline $\mathrm{L}$ & & & $-0.462( \pm 0.330)$ \\
\hline TOC & & & $-0.253^{* * *}( \pm 0.464)$ \\
\hline CHAIN & $-0.045( \pm 0.046)$ & & \\
\hline INTL & $0.28401^{* *}( \pm 0.088)$ & & \\
\hline CLASS & & $0.4023^{* *}( \pm 0.047)$ & \\
\hline $\mathrm{R}^{2}$ & 0.1421 & 0.09161 & 0.1931 \\
\hline Hausman test & $7.16^{* *}$ & $12.92^{* *}$ & $0.431^{*}$ \\
\hline Wooldridge test & 0.620 & 0.483 & $181.21^{* *}$ \\
\hline Heteroscedasticity test & $143.6^{* *}$ & $160.12^{* *}$ & 0.342 \\
\hline
\end{tabular}

Survey Data, 2015

Note: (a). *,** and *** denote statistical significance at $10 \%, 5 \%$, and $1 \%$ level of significance, respectively and (b) Standard errors in parenthesis.

$$
\mathrm{AD}=-0.703+0.95961 \mathrm{MS}+0.004 \mathrm{PF}+1.325 \mathrm{CR}_{4}-2.0181 \mathrm{CR}^{2}{ }_{4}-0.0231 \mathrm{SG}+0.149 \mathrm{ISAG}+0.4023 \mathrm{CLASS}
$$
.......................................................................

Analysis of the regression equation shows that advertising depends on the trends in market share, profitability, concentration ratio, sales growth rate and industry sales growth rate.However, further analysis indicate that advertising is affected positively by the metal enterprises market share, profitability, market concentration, industry sales growth and class (Table 4). The enterprises with greater market shares and higher star class ratings tend to have higher advertising expenditures.

\subsection{Business Awareness, Product Quality, Alliances and Efficiency}

Being aware of competitors' products and product quality was potentially very important and strategic for all firms. Firms were classified as having a high 'business awareness' if they responded with either excellent or very good for all these categories. As table 5 illustrates, there is a higher proportion of firms with high business awareness in the two larger size categories than in the smaller.

Table 5: Business Awareness by Firm Size

\begin{tabular}{|l|l|l|l|l|l|}
\hline FEATURE & ALL & MICRO & SMALL & MEDIUM & LARGE \\
\hline $\begin{array}{l}\text { Proportion of firms with high business } \\
\text { awareness }\end{array}$ & 0.64 & 0.22 & 0.61 & 0.84 & 0.87 \\
\hline Aware of global best practices & 0.61 & 0.18 & 0.53 & 0.85 & 0.86 \\
\hline Subsidized transfer of tech & 0.58 & 0.87 & 0.82 & 0.32 & 0.28 \\
\hline Management training & 0.9 & 0.81 & 0.86 & 0.95 & 0.97 \\
\hline Training proramme for workshop & 0.83 & 0.92 & 0.89 & 0.77 & 0.72 \\
\hline
\end{tabular}

Survey Data, 2015

There is a similar relationship between firm size and firm awareness of global best practice. $86 \%$ of large and macro firms claim to be aware of global best practice in contrast to $18 \%$ and $53 \%$ of micro and small firms respectively. Firms were then asked about areas requiring support by government, institutions and multilateral organizations in order to replicate best practice. Provision of affordable loans was the dominant answer for all firms across all size categories. Other support areas included facilitating studies in relevant factory (61\%), subsidized transfer of technology (58\%) and organizing workshops for business trainings (83\%).

Business networks and alliances potentially play an important role in sharing information between firms, consequently influencing stocking and pricing decisions. Firms were asked whether they had alliances with any other firms. $38 \%$ of firms responded affirmatively.

Table 6: Alliances and Networks by Firm Size

\begin{tabular}{|l|l|l|l|l|l|}
\hline & ALL & MICRO & SMALL & MEDIUM & LARGE \\
\hline Alliances & 38 & 4 & 8 & 30 & 58 \\
\hline Networks & 34 & 6 & 11 & 27 & 56 \\
\hline
\end{tabular}

Survey Data, 2015 
From table 6, more large firms were involved in alliances than smaller firms. Ascertaining whether business alliances and networks are linked to sound firm performance is difficult to conclude. This is because these dimensions of firm behaviour are hard to measure so the result may be misleading. The second point is that the effects of these dimensions of firm behaviour may not be picked up in underlying efficiency. They may for example affect the amount of its capital stock or the scale of its operations, factors that are captured by other variables in the regression. Finally it is possible that developing networks meets other objectives than firm performance and that these objectives can only be met at the expense of underlying firm efficiency. These are issues which require further investigation.

\subsection{Price setting strategies}

A part from the forces of demand and supply dictating market prices for the Metal products, the study revealed that the prices of certain qualities of steel products and high end flat steel/aluminium products was determined through vertical coordination. Table 7 shows the data.

Table 7: Price Determination Method

\begin{tabular}{|l|l|l|l|}
\hline Business Size & Price determination method & Frequency & Percent \\
\hline Large scale & vertical coordination & 139 & 56 \\
\hline Medium scale & vertical coordination & 60 & 24 \\
\hline Small scale & Inter-enterprise collusion & 30 & 12 \\
\hline Micro scale & Business association guidelines & 20 & 8 \\
\hline Total & & $\mathbf{2 4 9}$ & $\mathbf{1 0 0}$ \\
\hline
\end{tabular}

Survey Data, 2015

Such joint decision making process suggests vertical co-ordination in which the sellers get the goods they need at their preferred prices and the suppliers receiving their desired market prices. This finding supports the conclusion of (Koutsoyianni's, 1993, cited in Kibwage 2008) observation that no industry is perfectly competitive. Inter-enterprise collusion (12\%) and business association guidelines (8\%) were less preferred as methods of setting prices. This can be attributed to the competitive nature of the market for Metal products in Kakamega County.

Despite equality in the prices of individual products sold at different enterprise branches in different market segments (Kakamega and Mumias), it was realized that some enterprises sold more of the metal products than others. Such differences occurred due to locational differentiation and economies of large scale sales, which made it possible for some of the Metal products to be transferred from one branch to another where demand for such products were relatively higher.

Table 8: Preffered Metal Products

\section{Survey Data, 2015}

\begin{tabular}{|l|l|l|}
\hline Metal Products & Frequency & Percent \\
\hline Flat Steel Product & 131 & 52.60 \\
\hline Long Steel Product & 75 & 30.12 \\
\hline Pipes and Tubues & 15 & 6.03 \\
\hline Short Steel Product & 28 & 11.25 \\
\hline Total & $\mathbf{2 4 9}$ & $\mathbf{1 0 0 . 0}$ \\
\hline
\end{tabular}

The respondents were asked to estimate the proportion of metal products preferred by customers. This was meant to generate information on the likelihood of collusive behavior based on demand conditions. The classification was based on general sorting of metal products sold in four broad categories thus flat, long, short steel products and pipes and tubes. This classification was adopted because all products sold fell into the four categories.

The results indicate (Table 8) that most enterprises prefer to stock flat steel products at $52.6 \%(\mathrm{n}=131)$ followed by long steel products at $30.12 \%(\mathrm{n}=75)$. The preference of flat steel products over the rest could be attributed to high demand for such products. This further escalates the risk of collusion among enterprises dealing in such products since demand for these products would

not be affected considerably due to price changes.

\subsection{Marketing Trainings}

The respondents were asked whether they had ever attended trainings on marketing. The results from Table 9 indicate that $46.5 \%(\mathrm{n}=116)$ had never attended training on marketing, 24.5\% $(\mathrm{n}=61)$ had been trained at least once while $28.5 \%(\mathrm{n}=71)$ had been trained at least twice marketing. 
Table 9: Frequency of Attending Marketing Trainings

Survey Data, 2015

\begin{tabular}{|l|l|l|}
\hline \multicolumn{1}{|c|}{ Visits } & Frequency & Percent \\
\hline Never & 116 & 46.5 \\
\hline Once & 61 & 24.5 \\
\hline Twice & 71 & 28.5 \\
\hline 5 & 1 & 0.5 \\
\hline Total & $\mathbf{2 4 9}$ & $\mathbf{1 0 0 . 0}$ \\
\hline
\end{tabular}

The high proportion of respondents, who have never been trained on marketing points to the challenges facing micro, small and medium enterprises in Kenya and in Africa in general. This finding is also in line with the findings of the, (Worldbank, 2014). which sites over-reliance on local markets due to the absence of marketing skills. The lack of training on marketing could be attributed to weak or non-existent business associations for the dealers in Metal products as well as little or no support from the National/County Government trade authorities.

\subsection{Other product promotion approaches}

The respondents were asked about the various approaches they employed to create awareness for their metal products.

Table 10: Approaches Used to Create Awareness for Products

Survey Data, 2015

\begin{tabular}{|l|l|l|}
\hline Approaches & Frequency & Percent \\
\hline Giving discounts & 77 & 31.0 \\
\hline Free samples & 13 & 5.2 \\
\hline Personal selling & 44 & 17.6 \\
\hline Print and digital advertising & 6 & 2.4 \\
\hline Displaying products & 109 & 43.8 \\
\hline Total & $\mathbf{2 4 9}$ & $\mathbf{1 0 0 . 0}$ \\
\hline
\end{tabular}

The results from table 10 indicate that $43.8 \%(n=109)$ of the metal enterprises create awareness by displaying their products, $31 \%(n=77)$ do so by giving out discounts, $17.6 \%(n=44)$ use personal selling to create awareness for their products, $5.2 \%(\mathrm{n}=13)$ give free samples and $2.4 \%(\mathrm{n}=6)$ use print and digital advertising.

The results indicate that displaying products and giving discounts are powerful tools of advertising and creating demand for the dealers of Metal products. Displaying products gives customers a chance to consider the physical characteristics of the items on sale and to determine their durability based on tensile strength of the metals used to produce the products. Giving discounts entices customers to purchase the products because of the perceived savings. Respondents were asked about the marketing challenges they faced in their operations. This was essential because the challenges directly or indirectly influence the type of product and sales promotion policies as well as price determination method all of which are dimensions of conduct.

Table 11: Marketing challenges and approaches used to address them

\begin{tabular}{|l|l|l|}
\hline Marketing Challenges & Frequency & Percent \\
\hline Limited market information & 44 & 17.6 \\
\hline Limited marketing networking & 73 & 29.5 \\
\hline Over reliance on local markets & 67 & 26.9 \\
\hline Poor marketing skills & 40 & 16.0 \\
\hline Fierce competition & 25 & 10.0 \\
\hline Total & $\mathbf{2 4 9}$ & $\mathbf{1 0 0 . 0}$ \\
\hline Approaches used to address marketing constraints & Frequency & Percent \\
\hline & $\mathbf{3}$ & $\mathbf{1 . 2}$ \\
\hline Analyzing market needs and competition & 81 & 32.4 \\
\hline Market targeting & 76 & 30.5 \\
\hline Strategic market positioning & 1 & .5 \\
\hline Differentiated marketing/concentrated Marketing for specialised products & 31 & 12.4 \\
\hline Participating in trade fairs and trade exhibitions & 48 & 19.2 \\
\hline Forming local marketing associations & 9 & 3.8 \\
\hline Total & $\mathbf{2 4 9}$ & $\mathbf{1 0 0 . 0}$ \\
\hline
\end{tabular}

Survey Data, 2015

The results from table 11 show that $17.6 \%(n=44)$ of the respondents cited limited market information availed to them, $29.5 \%(n=73)$ face limited marketing networking, $26.9 \%(n=67)$ rely on the local markets, while $16.0 \%(n=40)$ have poor marketing skills and $10 \%(n=25)$ suffer from fierce competition. 
The results point to the fact that improving and strengthening marketing networks and availing reliable market information can help dealers of Metal products to expand into new markets thus helping to reduce their reliance on local markets. Expanding market opportunities also helps to reduce the fierce competition which can kill enterprises (Tung 2008)

On approaches used to address identified marketing constraints, $32.4 \%(\mathrm{n}=81)$ of the respondents analyzed market needs and competition trends, $30.5 \%(\mathrm{n}=76)$ dealt in products targeting certain markets, $0.5 \%$ $(\mathrm{n}=1)$ located their business at strategic places, $12.4 \%(\mathrm{n}=31)$ practiced differentiated marketing/concentrated marketing for specialized products, $19.2 \%(\mathrm{n}=48)$ participated in trade fairs and trade exhibitions to overcome the constraints, while $3.8 \%(n=9)$ formed local marketing associations to address the constraints.

Therefore, business development services aiming at providing a mix of marketing training and capacity development in product development should therefore be prioritized by trade and business authorities.

To investigate whether the enterprises included in the study served other markets outside the study areas and the effect of the same on their growth a cross-tabulation was done on the two variables. The results indicate that most of the firms have grown by $50 \%$ to $75 \%$ since 2012 with firms serving customers outside Kakamega County favored. Table 12 presents the results.

Table 12: Cross-tabulation of Growth vs Market Served outside the County

\begin{tabular}{|c|c|c|c|c|c|c|c|}
\hline & \multicolumn{5}{|c|}{ Growth from 2012} & \multirow[t]{2}{*}{ Total } \\
\hline & & $<25 \%$ & $25 \%-50 \%$ & $50 \%-75 \%$ & $75 \%-100 \%$ & $>100 \%$ & \\
\hline \multirow{2}{*}{$\begin{array}{l}\text { Does business serve other makets } \\
\text { outside Kakamega Municipality }\end{array}$} & Yes & 11 & 35 & 42 & 22 & 24 & 134 \\
\hline & No & 5 & 37 & 37 & 21 & 15 & 115 \\
\hline \multicolumn{2}{|l|}{ Total } & 16 & 72 & 79 & 43 & 39 & 249 \\
\hline
\end{tabular}

Survey Data, 2015

The results confirm the findings of (Tung, 2008) that serving small localized markets is an impediment to business growth. Thus for firms to be successful, they must focus on expanding their markets and penetrating into new market niches. Customers interviewed at point of sale on Metal products provided varying responses. Table 13 presents the results.

Table 13: Customers Views about Metal Products

\begin{tabular}{|l|l|l|}
\hline Customer responses & Number & Percentage (\%) \\
\hline Seen and bought Metal products & 95 & 38.18 \\
\hline Seen and had not bought & 4 & 1.8 \\
\hline Had used Metal products in construction & 82 & 32.72 \\
\hline Had used Metal products in Agriculture & 68 & 27.27 \\
\hline Total & $\mathbf{2 4 9}$ & $\mathbf{1 0 0}$ \\
\hline
\end{tabular}

Survey Data, 2015

The results show that a significant proportion of customers $38.18 \%(\mathrm{n}=95)$ had seen and bought Metal products, while $32.72 \%(\mathrm{n}=82)$ had used Metal products in construction and $27.27 \%(\mathrm{n}=68)$ had used them in agriculture. The findings confirm the World Steel Association (2014) findings that usage of Metal products in various sectors is on the rise.

The study results show that customers who were not able to afford Metal products resorted to alternative items made from plastics and wood. Although plastics and wood items were outside the scope of this study, their competition with the metal items was of great significance because of their potential to influence conduct, hence an investigation into their ranking by consumers against the metal products was inevitable. Results of the ranking are displayed in Table 14.

Table 14: Ranking of Metal Products vis a vis Plastic and Wooden

\begin{tabular}{|c|c|c|c|c|}
\hline Item & \multicolumn{3}{|l|}{ Rank } & Highest frequency \\
\hline & $1^{\text {st }}$ & $2^{\text {nd }}$ & $3^{\text {rd }}$ & \\
\hline Metal & $90(36 \%)$ & $110(44 \%)$ & $50(20 \%)$ & $110(44 \%)$ \\
\hline Plastic & $99(40 \%)$ & $57(25 \%)$ & $92(37 \%)$ & $99(40 \%)$ \\
\hline Wooden & $60(24 \%)$ & $77(31 \%)$ & $107(43 \%)$ & $107(43 \%)$ \\
\hline & 249 & 249 & 249 & \\
\hline
\end{tabular}

Survey Data, 2015

Basing their views on affordability of the products, $40 \%$ of the interviewed customers ranked plastic products the leading. Metal products were however ranked second by $44 \%$ of the customers followed by wooden products which were ranked the third by $43 \%$ of the customers. The $36 \%$ of the interviewed customers, who ranked metal products the leading, noted that the products were unique, attractive and stronger than plastic products. 
The $20 \%$ of customers who ranked Metal products the third based their ranking on durability in relation to Metal products. They noted that metal products were more durable than plastic products. A similar situation exists in Tanzania and Uganda where competition between metal, wooden and plastic commodities was identified by the OECD (2012) as one of the bottlenecks for production and marketing of metal products.

Respondents were asked to list their preffered suppliers of metal products. This was essential since dominant suppliers could capture large market shares thus leading to uncompetitive practices in coduct such as collusion and vertical coordination. The results in table 15 show that enterprises dealing in assorted iron sheets products prefer to be supplied by Mabati Rolling Mills (51\%), those dealing in assorted steel bars, pipes, tubes and boilers prefer Steel Centre $(69 \%)$ and $58 \%$ respectively, while those dealing in bathroom accessories prefer the Internationally recognized Peglar Brands (88\%).

Table 15: Preferred Supplies of Metal Products

\begin{tabular}{|l|l|l|}
\hline Products & Preferred supplier & \% \\
\hline \multirow{4}{*}{ Assorted corrugated iron sheets } & Mabati Rolling Mills & 51 \\
\cline { 2 - 3 } & Maisha Dumu & 18 \\
\cline { 2 - 3 } & Tembo & 10 \\
\cline { 2 - 3 } & Nyumba & 21 \\
\hline \multirow{2}{*}{ Assorted Steel bars } & Devki & 31 \\
\cline { 2 - 3 } & Steel centre & 69 \\
\hline \multirow{3}{*}{ Pipes, tubes and boilers } & Mabati Rolling Mills & 12 \\
\cline { 2 - 3 } & Devki & 30 \\
\cline { 2 - 3 } & Steel centre & 58 \\
\hline \multirow{2}{*}{ Bathroom accessories } & Peglar (UK) & 88 \\
\cline { 2 - 3 } & China branded & 12 \\
\hline
\end{tabular}

Survey Data, 2015

Furthermore, the source of marketed metal products influences sales and advertising expenditures, which suggests that products sourced from known suppliers such as Mabati Rolling Mills (MRM), have a competitive edge over non-branded competitors, enabling them to achieve higher market shares.

In summary, the determination of prices through vertical coordination points to existence of imperfect competition in the market for metal products in Kakamega County, Kenya.

\section{Conclusion}

The results for this study indicate that conduct in the retail market for metal products was influenced mainly by product promotion (displaying and giving discounts) and business networks while prices were determined through a mix of strategies including vertical coordination and collusion. The determination of prices through vertical coordination points to existence of imperfect competition in the market for metal products in Kakamega County, thus confirming (Koutsoyianni's, 1993) observation that no industry is perfectly competitive.

The popularity of product promotion approaches such as displaying of products and offering discounts shows the growing acceptance of the need for more aggressive marketing methods in order to grow market shares. In addition, business alliances and networks are considered in the modern market place as a means of sharing information about market dynamics of metal products in Kakamega County. Therefore, business alliances and networks are expected to continue exerting influence on the conduct of market participants both in the short and long-run.

\section{Recommendations}

The foregoing analysis can inform policy decisions in several respects. First, given the bidirectional relationships between market conduct, structure and their profitability (performance), there is need for keen evaluation of the market conduct in order to formulate appropriate measures to encourage effective competition.

Secondly, there is need to formulate regulations requiring prices for metal products be displayed and that standard weights and measures be used in the entire retail market. This can ensure that the consumer is given the necessary market information in order to make rational decisions. Thirdly, appropriate tariff rates for information, communication and technology as well as social media should be formulated to contribute to consumer enlightenment and product promotion. Finally, there is need for continuous reduction in opportunities for exploiting imperfectly informed buyers and sellers further helping to maintain competitive business conduct as well as markets. 


\section{References}

[1] Aghion, Bloom, Blundell, \& Griffith. (2005). Competition and innovation:an inverted-U relationship. Quarterly Journal of Economics , 701-728.

[2] Ariff, M. \&. (2008). Cost and Profit Efficiency of Chinese Banks: A non-parametric analysis. China Economic Review, $260-273$.

[3] Bain, J. (1951) "Relation of Profit Rate to Industry Concentration", Quarterly Journal of Economics, Vol. 65, pp. 293-324.

[4] Bain, J. S. (1959), Industrial Organization. New York: Wiley

[5] Byaruhanga. (2002). Structure and Performance of Fish Market in Lake Victoria Region. Kisumu: Maseno University.

[6] Clay, K. A. (2003). Further Test of Static Oligopoly Models:Whiskey. Journal of Industrial Economics, 151-166.

[7] CGK, (2013). Kakamega County Intergrated Development Plan (CIDP). Kakamega Town: Kakamega County, Kenya.

[8] Charmberlin, E. (1933). Theory of Monopolistic Competition, Harvard University.

[9] Cochran, WG (1963). Sampling Techniques, 2nd Ed., New York: John Wiley and Sons, Inc.

[10] Delloite. (2013). The Iron and Steel Industry in Turkey. Turkey: Investment Support and Promotion Agency of Turkey.

[11] Delloitte. (2015). The Iron and steel industry in Turkey: Investiment support and promotion agency of Turkey. Ankara: Delloitte.

[12] Durling, J. P., \& Thomas, P. J. (2006). The trade effects associated with an antidumping epidemics: The Hot-Rolled steel market. European journal of political economy, 675- 695.

[13] GoK. (2009). Economic Survey. Naairobi: Government Printer.

[14] GoK. (2010). Economic Survey. Naairobi: Government Printer.

[15] GOK. (2014). Economic Survey. Nairobi: Government Printers.

[16] GOK. (2015). Economic survey. Nairobi: Government Printers.

[17] Greer, G. (1971). Advertising and Market Concentration. Southern Economist , 19-32.

[18] Hanh, F. (2005). Testing for profitability and contestability in banking. Austrian Journal of economic research, 252-261.

[19] Hrazdil, \& Zhang. (2012). The Importance of Industrial Classification in Concentrating ratios. Economic Letters , $224-227$.

[20] JMD. (2015, January 8). The falling Oil prices might affect Steel demand. Retrieved from Japan Detal http://www.japanmetaldaily.com/metal/2015/steel_news_20150108_1.html

[21] Kibwage, (2008). Structure and Performance of Formal Retail Market for Bamboo Products in Kenya. Scientific Research and Essay Vol.3(6), 229-239.

[22] Khambampati, U. S. (1996). Industrial concentration and performance: a study of the structure, conduct, and performance of Indian industry. New Delhi: Oxford University Press.

[23] KPSA. (2015). The Voice of Private sector. Nairobi: KPSA

[24] Konings, J. A. (2005). Antidumping protection and markups of domestic firms. journal of international economics, 151-165.

[25] Kothari, C. (2004). Research methodology . Methods and techniques 2nd ED). New Delhi, India: New Age International.

[26] Koutsoyianni's. (1993). Industry Observations; Observations and Conclusions. New Delhi.

[27] Liebman, B. H. (2006). safeguards, china, and price of steel. Weltwirtschaftliches archiv, 354-373.

[28] Ma, Y. A. (2008). determinants of international insurers' Participation in foreign markets. journal of risk and insurance, 2.

[29] OECD. (2012). The future of Steel industry: selected trends and policy issues: Directorate for Science,Technology and Industry. Paris: OECD Publishing.

[30] OECD (2015d), "Excess capacity in the global steel industry and the implications of new investment projects", OECD Science, Technology and Industry Policy Papers, No. 18, OECD Publishing, available at: 21TUhttp://dx.doi.org/10.1787/5js65x46nxhj-en

[31] Puller, S. L. (2007). pricing and firm conduct in jcalifornia's deregulated electricity market. review of economics and statistics, 7587.

[32] Tregenna, F. (2009). the fat years: the structure and profitability of the US banking sector in the pre-crisis period. cambridge journal of economics, 4-10.

[33] Tung. (2008). The Market Structure, Conduct and Perfomance Pardigm Re-applied to the Internation Tourist Hotel Industry. Scientific Research and Essay, 229-239.

[34] Scherer, \& Ross. (1990). Industrial Market Structure and Economic Performance. Boston: Houghton Mifhin Company.

[35] WSA. (2015). World Steel Outlook 2015-2016. Metal Expert's Conference, April 20-21, 2015, Kiev, Ukraine.

[36] WorldBank. (2014). Uncovering Developing Countries. Woshington: The World Bank.

[37] UNIDO. (2011). Industrial policy for Prosperity . Vienna: UNIDO.

[38] UNIDO. (2015). Together for a sustainable future: Annual Repoprt 2015. Vienna: UNIDO.

[39] Yu, P., \& Neus, W. (2005). market structure, scale efficiency and risk as determinants of Germanybanking profitability.University of Tubingen working paper, 294. 